\title{
Penerapan Total Quality Managemen sebagai Pengembangan Budaya Mutu Sekolah dalam Meningkatkan Prestasi Siswa di SD Al Hikmah Surabaya
}

\author{
Wahyuni Ahadiyah \\ Program Studi Pendidikan Agama Islam Universitas Islam Lamongan \\ E-mail: wahyuniahadiyah@unisla.ac.id
}

\begin{abstract}
Abstrak: Latar belakang masalah penelitian ini adalah melihat krisis multidimensional yang melanda bangsa Indonsia. Sehingga perlu peningkatan mutu pendidikan sebagai upaya peningkatan kualitas sumber daya manusia Indonesia secara menyuluruh. Tujuan penelitian ini dilakukan: 1) untuk mengetahui bagaimana budaya mutu sekolah di Al Hikmah Surabaya, 2) mengetahui bagaimana prestasi siswa Al Hikmah Surabaya, 3) bagaimana upaya pengembangan budaya mutu sekolah di Al Hikmah Surabaya dalam meningkatkan prestasi siswa. Penelitian ini menggunakan pendekatan kualitatif dengan rancanngan studi kasus. Pengumpulan data dilakukan melalui Wawancara mendalam, Observasi partisipatif, dan Studi dokumentasi. Teknik analisis data melalui tahapan reduksi, display, dan veriifkasi. Sedangkan untuk menguji keabsahan data dilakukan dengan cara Triangulasi. Penelitian ini difokuskan pada: 1). Budaya mutu sekolah di SD Al Hikmah Surabaya yang memiliki karakteristik berikut: (a) Sekolah fokus pada kepuasan pelanggan, (b) Mengutamakan pentingnya sumber daya manusia, (c) Memiliki standart kinerja yang tinggi, (d) Budaya sekolah terdefinisi degan jelas. 2). Prestasi siswa SD Al Hikmah dapat dilihat dari: (a) prestasi yang meliputi akdemik, (b) prestasi non akademik, termasuk kegiatan ekstrakulikuler, dan (c) ibadah dan akhlak yang sesuai dengan tujuan sekolah, "Berbudi dan Berprestasi". 3). Upaya mengembangkan budaya mutu di SD Al Hikmah fokus pada: a) Orientasi mutu pendidikan, b) Pelayanan sekolah, c) Komitmen sekolah terhadap mutu, d) Kurikulum sekolah.
\end{abstract}

Kata Kunci: Budaya, Mutu Sekolah, Prestasi Siswa

Abstract: The background of this study is to look at the multidimensional crisis hitting the nation. On this stand it is necessary to improve the quality of education as an effort to improve the quality of Indonesian human resources comprehensively. The objectives of this study are: 1) to find out the school quality culture in SD Al Hikmah Surabaya, 2) to find out the students' achievement in Al Hikmah Surabaya?, 3) to find out the efforts in developing the school quality culture in SD Al Hikmah Surabaya in increasing student achievement. This study uses a qualitative approach with a case study design. Data collection is carried out through in-depth interviews, participatory observations, and documentation studies. Data analysis techniques are through such stages as reduction, display, and verification. Meanwhile, to test the validity of the data is carried out through triangulation. This study is focused on: 1). The school quality culture in SD Al Hikmah Surabaya which has the following characteristics: (a) Focusing on customer satisfaction, (b) Prioritizing the importance of human resources, (c) Having high performance standards, (d) School culture is clearly defined. 2). Student achievements in SD Al Hikmah could be seen from: (a) achievements which include academics, (b) non-academic achievements, including extracurricular activities, and (c) worship and morals which are in accordance 
with school goals, "Being virtuous and obtaining achievement" 3). The ffforts to develop a quality culture in SD Al Hikmah focus on: a) Orientation of educational quality, b) School services, c) School commitment to quality, d) School curriculum.

Keywords: Culture, School Quality, Student Achievement.

\section{Pendahuluan}

Salah satu isu penting dalam penyelenggaraan pendidikan saat ini adalah peningkatan mutu pendidikan. Karena peningkatan mutu pendidikan merupakan sasaran pembangunan di bidang pendidikan nasional dan merupakan bagian integral dari upaya peningkatan kualitas manusia Indonesia secara menyuluruh. ${ }^{1}$

Mutu adalah yang membedakan antara yag baik dan sebaliknya. Sehingga mutu jelas sekali merupakan hal pokok yang akan menjamin perkembangan sekolah. ${ }^{2}$ Sebuah organisasi harus memahami bahwa sebagian besar rahasia mutu berakar dari mendengar dan merespon secara simpatik terhadap kebutuhan dan keinginan pelanggan.

Karena semakin tinggi budaya mutu diterpkan, akan semakin tinggi pula keinginanan seseorang untuk selalu berprestasi dan melakukan perbaikan. ${ }^{3}$ Jika budaya sekolah sudah mapan, siapapun yang masuk dan bergabung ke sekolah itu hampir secara otomatis akan mengikuti tradisi yang telah ada. Penguatan pendidikan dengan mengacu pada mutu, dan prestasi siswa dalam konteks sekarang dirasa sangat relevan untuk mengatasi krisis multidimensi yang tengah melanda. Krisis akhlak yang menimpa kalangan pelajarpun sudah tidak jarang kita temui seperti penggunaan obat-obatan terlarang, kejahatan seksual, bergaya hidup metrealis, hedonis dan susah dikendalikan.

Pergeseran dari kurikulum 2006 ke kurikuum 2013 menuntut pengembangan budaya mutu mengacu pada ruang lingkup pengembangan kurikulum 2013. Peningkatan proses pelayanan yang lebih inovatif kepada siswa menjadi tuntutan utama. Mengembangkan pembelajaran yang berpusat pada guru menuju pembelajaran berpusat pada siswa. Pembelajaran menuntun siswa untuk mencari tahu (discovery learning) bukan diberi tahu. Segi penilaian, menekankan pada pertanyaan yang membutuhkan pemikiran mendalam bukan hafalan. Kegiatan ekstrakurikuler tidak cukup kegiatan pramuka namun perlu kegiatan yang mampu mengembangan potensi siswa di bidang lain. ${ }^{4}$

Menurut Bank Dunia ada empat faktor penghambat mutu pendidikan, yaitu: (1) kompleksitas pengorganisasian pendidikan dasar antara Depdiknas dan Depdagri serta Depag, (2) praktik manajemen yang sentralistik pada tingkat SD dan SMP, (3) praktik penganggaran yang terpecah dan kaku, (4) manajemen sekolah yang tidak efektif.

\footnotetext{
1 Mulyasa, MenjadiKepala Sekolah Profesional dan menyukseskan MBS dan KBK (Bandung: Remaja Rosdakarya, 2005), 31.

${ }^{2}$ Edward Sallis, Total Quality Management in Education: Managemen Mutu Pendidikan (Jogjakarta: IRCiSoD, 2006), cet. Ke-1, 30-32.

${ }^{3}$ Siswanto, "Budaya Madrasah: Strategi Pengembangan Mutu Pendidikan”, Jurnal Tadris, Vo. 7, No. 2 (2012), 217.

${ }^{4}$ Teguh Riyanta, "Mengembangkan Budaya Mutu Sekolah melalui Kepemimpinan Transformasional”, Jurnal Manajemen Pendidikan, Vol. 12, No. 2, (2016), 37-38.
} 
Paradigma baru manajemen pendidikan saat ini memberikan keleluasaan kepada sekolah dalam mengelola sendiri segala kebutuhannya untuk meningkatkan mutu pendidikan. Namun pada kenyataannya pendidikan belum memenuhi harapan masyarakat, bahkan sumber daya manusia yang dihasilkan belum memenuhi syarat pasar tenaga kerja. Dengan demikian, sekolah harus melakukan perbaikan yang terus menerus. Peningkatan mutu pendidikan yang telah diupayakan oleh pemerintah melalui MPMBS harus dibarengi pula oleh peningkatan mutu dan memperbaiki manajemen sekolah. Para manajer pendidikan dituntut untuk mencari dan menerapkan manajemen yang berorientasi pada mutu dan perbaikan yang berkesinambungan.

Kegagalan dalam memperbaiki mutu pendidikan akibat manajemen yang lemah akan menimbulkan kegagalan generasi baik dalam dimensi mikro maupun dimensi makro. Oleh karena itu, manajemen sekolah harus mengembangkan kreativitas, inovasi, modernisasi, dan terfokus pada pelanggan pendidikan. Manajemen yang bertumpu pada pemenuhan kebutuhan pelanggan dan perbaikan yang berkesinambungan adalah Manajemen Mutu Terpadu (Total Quality Management). Dalam pengertian lain, Santosa dalam menyatakan bahwa Manajemen Mutu Terpadu (MMT) merupakan sistem manajemen yang mengangkat kualitas sebagai strategi usaha dan berorientasi pada kepuasan pelanggan dengan melibatkan seluruh anggota organisasi.

Pengembangan budaya mutu pendidikan sekolah melalui penerapan manajemen mutu terpadu di sekolah sangat tepat, karena budaya mutu merupakan suatu sistem yang tidak hanya mengurangi masalah-masalah pendidikan, tetapi sekaligus sebagai model yang mengutamakan perbaikan berkelanjutan. Manajemen mutu menawarkan filosofi, metode, dan strategi baru perbaikan mutu pendidikan. Pengembangan budaya mutu sekolah dalam pendidikan dilaksanakan dengan meningkatkan pelayanan untuk memenuhi keinginan dan harapan dari para pelanggan. Menurut Sallis pelanggan dalam pendidikan dibagi menjadi tiga kelompok, yaitu: 1) pelajar yang secara langsung menerima jasa, 2) orangtua, gubernur atau sponsor pelajar yang memiliki kepentingan langsung secara individu maupun institusi, 3) pihak yang memiliki peran penting, meskipun tak langsung seperti pemerintah dan masyarakat secara keseluruhan. Keragaman pelanggan tersebut membuat seluruh institusi pendidikan harus lebih memfokuskan perhatian mereka pada keinginan para pelanggan dan mengembangkan mekanisme untuk merespon mereka. Sekolah sebagai salah satu lembaga pendidikan harus dapat mengadopsi penerapan manajemen mutu terpadu dengan melakukan perubahan budaya mutu pendidikan yang ada di sekolah menuju ke arah perbaikan.

Perbaikan yang terus menerus ini perlu dilakukan sehingga dapat meningkatkan mutu pendidikan sekolah, bukan hanya mutu dari peserta didik tetapi juga mutu dari tenaga pendidiknya. Untuk menghasilkan output pendidikan yang bermutu, maka elemen-elemen yang terlibat dalam dunia pendidikan harus bermutu dan berdaya guna. Elemen-elemen yang terlibat dalam dunia pendidikan salah satunya adalah tenaga pendidik atau guru merupakan salah satu faktor penentu keberhasilan pendidikan. maka kualitas guru perlu ditingkatkan, sehingga dapat menghasilkan output yang bermutu.

Salah satu teori manajemen yang banyak diterapkan dalam organisasi adalah teori manajemen mutu, yang saat ini disebut dengan Total Quality Management (TQM). Untuk mengimplementasikan dengan baik teori manajemen ini, diperlukan nilai-nilai yang menjadi 
budaya dalam organisasi tersebut. Budaya yang menyokong sistem manajemen tersebut kemudian disebut dengan budaya mutu. Dalam kaitan dengan TQM ini budaya mutu adalah suatu budaya yang memiliki tema sentral untuk peningkatan terus menerus (contiuous improvement).

Mutu atau kualitas pendidikan dikaitkan dengan tinggi-rendahnya prestasi yang ditunjukkan dengan kemampuan siswa mencapai skor tes dan kemampuan lulusan mendapatkan dan melaksanakan pekerjaan. Kemudian lebih lanjut Suprapto menyimpulkan bahwa pendidikan terkait dengan hasil belajar. Hasil belajar merupakan tingkah laku yang dapat dicapai dari suatu pengalaman dan biasanya mengarah kepada penguasaan pengetahuan, kecakapan, dan kebiasaan. Produk atau hasil pendidikan dipandang bermutu jika mampu melahirkan keunggulan akademik dan ekstrakulikuler peserta didik yang dinyatakan lulus untuk satu jenjang pendidikan atau menyelesaikan program pembelajaran tertentu. Keunggulan akademik dinyatakan dengan nilai yang dicapai peserta didik. Sedangkan keunggulan ekstrakulikuler dinyatakan dengan aneka jenis keterampilan yang diperoleh siswa selama mengikuti program di sekolah.

SD Al hikmah Surabaya merupakan sekolah yang berupaya mengembangkan budaya mutu pendidikan sekolah, melakukan perbaikan kinerja melalui pengembangan budaya mutu sekolah yang mengacu pada manajemen mutu terpadu. Hal ini menjadikan SD Al hikmah berhasil memperoleh juara I lomba budaya mutu sekolah tingkat provinsi di malang 2015 dan dilanjutkan juara II tingkat Nasional di Padang tahun 2015 sebagai kategori "the hwole caracter" atau katagori juara umum.

Pada tahun 2010 pula SD Al Hikmah Surabaya mendapatkan penghargaan dari Kementrian Pendidikan Nasinal atas upayanya dalam merintis, melaksanakan dan menerapkan pendididkan karakter bangsa. Pada tahun 2012 SD Al Hikmah Surabaya menjadi center of cambridge, hal ini terjadi atas kerjasama seluruh komponen yang ada di Al Hikmah Surabaya dan pihak terkait. Adanya pengukuran tersebut merupakan bukti bahwa SD Al Hikmah Surabayamerupakan sekolah yang memiliki kualitas unggul dari segi fasilitas, kurikulum, pelayanan, dan proses belajar mengajar. Di sisi lain, ternyata SD Al Hikmah Surabaya sudah mengembangkan kurikulum perpaduan kurikulum Departemen Pendidikan Nasional dengan kurkulum khas Al Hikmah, sehingga bisa memenuhi kompetensi sesuai quality assurance dengan standart nasional. Kurikulum khas Al Hikmah Surabaya memperkuat sentuhan pembinaan kepribadian muslim, dengan memegang teguh prinsip "learning is easy, and fun, all can and will learn, continuous progress, learn how to learn, dan student active learning”.

Hal menarik lainnya adalah tidak jarang ditemukan beberapa keluarga yang menyekolahkan anak-anaknya di SD Al hikmah Surabaya lebih dari satu anak. Meskipun dapat dikategorikan sekolah dengan biaya operasional pendidikan mahal. Sebagian dari orang tua Ada yang memiliki dua anak bahkan lebih dalam satu tingkat pendidikan dasar. Namun, ada yang berbeda jenjang pendidikan yaitu TK, SMP, atau SMA Al hikmah Surabaya.

Sejak berdirinya sekolah ini setiap tahunnya penerimaan siswa di SD Al Hikmah Surabayaberbeda-beda namun cenderung mengalami grafik kenaikan, hal ini menandakan bahwa sekolah mendapatkan kepercayaan dari orang tua untuk putra-putrinya bersekolah 
kembali di SD Al hikmah. Dalam pendidikan, jika suatu lembaga pendidikan telah mampu memenuhi kebutuhan pelanggannya, maka akan berdampak pada kelangsungan hidup bagi lulusan sekaligus lembaga pendidikan tersebut.

Amtu menyatakan bahwa mutu adalah panduan atau standardisasi sifat-sifat dari barang atau jasa yang menunjukkan kemampuannya dalam memenuhi kebutuhan pelanggan, baik kebutuhan langsung maupun tidak langsung atau yang dinyatakan maupun yang tersirat. Konsep mutu atau kualitas sangat bergantung pada sudut pandang setiap orang. Menurut Sallis mutu dalam pengertian absolut, didefinisikan sebagai sesuatu yang dibuat dengan sempurna dan dengan biaya yang mahal. Produk-produk tersebut dapat dinilai serta membuat puas dan bangga para pemiliknya.

Sedangkan konsep mutu dalam pengertian relatif menurut Umaedi bukanlah suatu sebutan untuk suatu produk atau jasa, tetapi pernyataan bahwa suatu produk atau jasa telah memenuhi persyaratan atau kriteria, atau spesifikasi yang ditetapkan (standar). Produk atau jasa tersebut tidak harus terbaik, tetapi memenuhi standar yang telah ditetapkan. Jadi tergantung standarnya yang telah ditetapkan, apakah standar tinggi, sedang, atau rendah. Juran berpendapat, bahwa karakteristik organisasi yang memiliki budaya mutu yang kuat adalah sebagai berikut; 1. Filosofi manajemen dijabarkan secara luas 2. Menekankan pentingnya sumber daya manusia berorganisasi 3. Memiliki sistem nilai yang kuat 4. Memiliki standar kinerja yang tinggi 5. Budaya organisasi terdefinisi secara jelas.

Edward Sallis, sekolah yang memiliki budaya mutu adalah ${ }^{5}$ Sekolah berfokus pada pelanggan, baik internal, maupun eksternal, Fokus terhadap upaya mencegah masalah atau yang dikenal dengan programp Zero De Fact (Kerusakan nol), ${ }^{6}$ Memiliki investasi sumber daya manusianya yang terus dijaga agar tidak samapai mengalami kerusakan, Memiliki strategi untuk mencapai kualitas, ditingkat pimpinan, tenaga akademik, maupun tenaga administratif, mengelolah keluhan sebagai umpan balik untuk mencapai kualitas dan memposisikan kegagalan sebagai instrumen perbaikan selanjutnya.

Memiliki kebijakan dalam perencanaan mencapai kualitas, baik jangka pendek, menengah, atau jangka panjang, Mengupayakan proses perbaikan dengan melibatkan semua komponen sesuai tugas dan fungsinya, Mendorong setiap yang dipandang memiliki kreatifitas, mampu menciptakan kualitas untuk merangsang yang lain agar dapat bekerja secara bermutu. Sekolah memperjelas tanggung jawab masing-masing termasuk arah kerja secara vertikal dan horizontal, memiliki strategi dan kriteria evaluasi yang jelas, menempatkan kualitas yang telah dicapai sebagai jalan perbaikan selanjutnya. Sehingga mamandang kualitas sebagai bagian integral dari budaya kerja serta melakukan peningkatkan mutu secara terus-menerus sebagai keharusan.

Faktor-faktor yang mempengaruhi budaya mutu sekolah adalah nilai-nilai dan misi organisasi, struktur organisasi, komunikasi, pengambilan keputusan, lingkungan kerja,

\footnotetext{
${ }^{5}$ Edward Sallis, Total Quality Management in Education: Managemen Mutu Pendidikan (Jogjakarta: IRCiSoD, 2006), cet. Ke-1, 32. Lihat Sudarwan Danim, Visi Baru Manajemen Sekolah, 2006,

6 Mustaqim, Sekolah/ Madrasah berkualitas dan berkarakter, Jurnal Pendidikan Agama Islam (Semarang : Fakultas Tarbiyah IAIN Walisong, 2012), 139.
} 
rekrutmen dan seleksi, perencanaan kurikulum, manajemen sumber daya dan anggaran, serta disiplin dan hubungan masyarakat.

Budaya Mutu ini juga dianggap memiliki peran dalam Meningkatkan Prestasi Siswa. Beberapa ahli memberikan definisi tentang prestasi,. Menurut Nana Sudjana, prestasi belajar adalah kemampuan yang dimiliki siswa setelah ia menerima pengalaman belajar. Menurut Mulyono Abdurrahman, prestasi belajar adalah kemampuan yang diperoleh anak setelah melalui kegiatan belajar. Menurut Syaiful Bahri Djamarah, prestasi belajar merupakan hasil dari suatu kegiatan yang telah dikerjakan atau diciptakan secara individu maupun secara kelompok.

Prestasi adalah hasil yang dicapai dari suatu kegiatan proses kegiatan belajar mengajar yang telah dilalui dan melalui bakat atau kemampuan yang dimiliki oleh siswa baik secara indifidu atau berkelompok.

Bisa kita simak melalui faktor-faktor yang Mempengaruhi Prestasi Siswa. Syah mengatakan bahwa prestasi belajar siswa dipengaruhi yaitu melalui faktor internal dan factor eksternal. Faktor internal sendiri meliputi jasmaniah atau lebih dikenal kesehatan dan cacat tubuh. Sedangkan faktor internal lainnya adalah dari segi psikologis yang meliputi tingkat intelegensi, perhatian, minat, bakat, motif, kematangan dan kesiapan. Faktor Eksternal yang terdiri dari faktor keluarga, faktor dari lingkungan sekolah, faktor masyarakat. Faktor eksternal siswa juga terdiri atas dua macam, yakni faktor lingkungan sosial dan faktor lingkungan non sosial.

Prestasi belajar sendiri di bagi ke dalam tiga macam prestasi diantaranya: prestasi yang bersifat kognitif (ranah cipta), prestasi yang bersifat afektif (ranah rasa), prestasi yang bersifat psikomotorik (ranah karsa). Suatu organsasi yang mempunyai budaya kerja yang tinggi, akan menuntut personelnya untuk memiliki komitmen yang tinggi dengan etos kerja yang tinggi pula. Hal ini juga dikatakan oleh Tony Bush dan Marianne Coleman, yang memberikan alasan mengapa nilai-nilai atau budaya yang dianut sekolah dapat mempengaruhi keunggulan dan prestasi karena nilai-nilai atau budaya dapat mempengaruhi cara bertindak seseorang.

\section{Budaya Mutu Sekolah SD al-Hikmah Surabaya}

Budaya mutu bisa berupa filosofi, keyakinan, sikap, norma, tradisi, prosedur, dan harapan yang tertanam dan berkembang di lingkungan anggota organisasi yang dipercayai bisa membentuk dan meningkatkan kualitas. Hal ini sangat penting untuk keberlangsungan proses pendidikan itu sendiri. Karena tanpa adanya sebuah budaya mutu maka pendidikan yang dihasilkan akan sama bahkan bisa tertinggal dari pada lembaga pendidkan lain terutama terkait dengan out put yang dihasilkan.

Budaya mutu sekolah SD Al Hikmah bisa dilihat dari paparan data yang diperoleh dari lapangan yang berkaitan dengan:

1. Karakteristik budaya mutu sekolah di SD Al Hikmah Surabaya

a. Sekolah fokus pada kepuasan pelanggan

b. Menekankan pentingnya sumber daya manusia. 
c. Memiliki standar kinerja yang tinggi.

d. Budaya-budaya sekolah terdefinisi secara jelas.

2. Prestasi siswa SD Al Hikmah Surabaya

Prestasi akdemik dan non akademik di SD Al Hikmah Surabaya terbukti dengan adanya beberapa penghargaan terlihat adanya House of Camp di halaman depan kantor SD Al Hikmah. Hal ini membuat motivasi siswa dan stakeholder sekolah untuk terus mencetak berabagai macam prestasi yang membanggakan. Sebagaimana prestasi lainnya yang diraih oleh sekolah, siswa, dan guru pendidik SD Al hikmah Surabaya yang telah dijelaskan pada bab pendahuluan sebelumnya.

Adapun upaya sekolah dalam pengembangan budaya mutu yang diterpkan SD Al Hikmah dapat dilihat sebagai berikut yaitu Orientasi mutu pendidikan, Pelayanan sekolah, Komitmen sekolah dalam menjalankan mutu pendidikan, dan Kurikulum pembelajaran

Menganalisis data budaya mutu sekolah di SD Al Hikmah Surabaya yang dapat dikatakan sebagai strategi mempertahankan dan meningkatkan budaya sekolah secara terus menerus. Hal ini sejalan pula dengan konsep Total Quality Manajemen (TQM) yang dikatakan Tjipto dan Diana (2002:21) sebagai berikut:

Total Quality Manajemen (TQM) merupakan sutau pendekatan dalam menjalankan sebuah usaha yang mencoba untuk memaksimumkan daya saing organisasi melalui perbaikan terus menerus atas produk, jasa, manusia, proses, dan lingkungannya. Singkatnya Total Quality Manajemen (TQM) merupakan system menajemen yang mengankat kualitas sebagai strategi usaha dan berorientasi pada kepuasan pelanggan terhadap barang dan jasa yang diberikan.

Temuan peneliti dengan memadukan teori Edward Sallis di atas, sekolah yang memiliki budaya mutu kuat memiliki indikator:

1. Sekolah berfokus pada pelanggan, baik pelanggan internal, maupun eksternal.

Ust. Sutaji, Wali kelas 2F memberikan pernyataan: "Terkadang kita mendapat laporan langsung dari wali murid, yang berterima kasih atas bimbingan kepada anak-anaknya yang mulai berubah menjadi baik".

2. Mengutamakan pentingnya sumber daya manusia.

Kepribadian ini sangat penting karena guru adalah sosok yang menjadi contoh untuk menghindaarkan dari sikap tidak terpuji. Usaha meningkatkan SDM ini tercermin dari beberapa kegiatan seperti KKG, pembinaan guru dan wali kelas berkelanjutan, rapat koordinasi, Halaqoh, mulai yang bersifat mingguan, bulanan, dan tahunan serta ditetapkannya standar mutu guru, dan seleksi calon PSB dengan rosedur yang jelas.

3. Memiliki standart kinerja yang tinggi.

Menurut Sudarwan Dawis, produk atau hasil pendidikan dipandang bermutu jika mampu melahirkan keunggulan akademik dan ekstrakulikuler peserta didik yang dinyatakan lulus untuk satu jenjang pendidikan. 
Hal ini tercermin dalam pengamatan peneliti dari beberapa standart mutu siswa semua disusun dilaksanakan dan dievaluasi setiap tahun, menerapkan standarisasi sekolah ISO.

4. Budaya sekolah terdefinisi degan jelas.

Tasmara mengungkapkan : Budaya berkaitan erat dengan persepsi nilai dan lingkungannya yang melahirkan makna dan pandangan hidup yang akan mempengaruhi sikap dan tingkah laku (the total way of life a poeple).

Dengan demikian apa yang diyakini dalam suatu sekolah akan mempengaruhi pola pandang dan tinggkah laku semua anggotanya. sebagaimana yang di kutip dari wawancara berikut:

"Semua yang sudah masuk di Al Hikmah harus mengikuti aturan dan budaya yang telah ada di Al Hikmah, Semua ada standard dan aturannya tidak bisa melakukan sesuai keinginannya sendiri. Karena ini dalam rangka pembelajaran keteladanan dan juga pembiasaan agar anak-anak juga mencontoh apa yang kita lakukan dengan baik".

Sedangakan tentang prestsi sendiri menurut Nana Sudjana, prestasi belajar adalah kemampuan yang dimiliki siswa setelah ia menerima pengalaman belajar.

Adapun prestasi akademik siswa SD Al Hikmah dapat dikategorikan unggul dengan melihat hasil yang dicapai siswa mampu melebihi kriteria ketuntasan yang ditetapkan:

"Semua KKM siswa adalah 8.0 kecuali Bahasa Jawa 6,5".

Selain prestasi akademik dan non akademik, yang terlihat adalah prestasi di bidang ibadah dan akhlakul karimah. Sebagaimana penjelasan dalam observasi berikut: Salah satu layanan sekolah dalam menjaga dan meningkatkann kualitas Ibadah dan akhlak siswa adalah dengan adanya program Subuh Call dan Bina karakter setiap hari.

Hal ini senada dengan yang diungkapkan oleh Syaifullah bahwa semakin kuat budaya dalam sebuah organisasi, semakin kuat pula dorongan untuk berprestasi. Karena dalam suatu lembaga terddiri dari kumpulan indifidu yang berbeda karakter dll, sehingga perlu ada pengakuan pandangan untuk mencapai tujuan agar tidak berjalan sendri-sendiri.

\section{Pengmbangan Mutu SD Al-Hikmah: Pendekatan Total Quality Managemen}

Dari hasil analisis kasus di atas, ditemukan beberapa Upaya pengembangan budaya mutu sekolah di SD Al Hikmah Surabaya

1. Orientasi mutu pendidikan

Umaedi menyampaikan bahwa Umaedi mendefinisikan mutu sebagai sifat-sifat benda, barang, atau jasa yang secara keseluruhan memberikan rasa puas kepada penggunanya karena telah sesuai atau melebihi apa yang telah dibutuhkan dan diharapkan. Untuk menjamin semua itu sekolah memiliki kebijakan mutu yang kemudian diturunkan dalam standart mutu guru dan standart mutu siswa serta menjabarkan proses dan target pendidikan yang dilakukan sekolah. Dalam hal ini orientasi pendidikan yang dilakukan sekolah dilihat dari input, proses pembelajaran dan output sekolah. 
2. Pelayanan sekolah

Ada beberapa faktor yang mempengaruhi siswa salah satunya faktor lingkungan sekolah. Ada beberapa pelayanan sekolah terhadap siswa, guru, dan orang tua sehingga berdampak positif sesuai wawancara berikut ini: "Soalnya sekolah ini tuh sering juara jadi aku kepingin kayak gitu. sekolah di sini pelejarannya menyenangkan ada main-mainan, terus ustadzahnya baik-baik semua". Hal ini didukung dari hasil wawancara dengan siswa lain sebagai berikut: "Senang belajar di sini karena kalau ada pelajaran sulit ustadzah gak pernah marah-marah."

3. Komitmen sekolah

Edward Sallis berpendapat, bahwasanya salah satu ciri sekolah-sekolah yang memiliki budaya mutu adalah berfokus pada pelanggan, SD Al Hikmah memiliki kebijakan mutu yaitu: berkomitmen kuat untuk: 1) meluluskan siswa-siswi yang berakhlakul karimah dan berprestasi akademik optimal, 2) mewujudkan pendidikan yang berorientasi global sehingga kompetitif di dunia, dengan berlandaskan nilai-nilai Islam dan kebangsaan, 3) memberikan layanan prima dengan mengutamakan kepuasan stakeholder. Lebih jelasnya bisa dilihat pada lampiran di belakang.

Sekolah mengutamakan lulusan siswa tidak hanya berprestasi akademik tetapi juga memiliki akhklah yang mulia, berkompetensi dan bersaing di tingkat dunia, dan untuk mewujudkannya, sekolah memberikan layanan prima bagi para stakeholder-nya.

\section{Kurikulum Sekolah}

Pada dasarnya kurikulum merupakan pengendali utama proses pembelajaran. SD Al Hikmah menerapkan juga mengembangkan kurikulum perpaduan kurikulum Departemen Pendidikan Nasional dengan kurkulum khas Al Hikmahdan pengembangan keterampilan hidup (life skills), kurikulum Cambridge International Primary Program (CIPP).

\section{Penutup}

Budaya mutu sekolah yang ada di SD Al Hikmah Surabaya memiliki karakteristik sebagai berikut antara lain perilaku warga sekolah yang sesuai dengan visi sekolah, mengutamakan pentingnya sumber daya manusia. memiliki standart kinerja yang tinggi, budaya sekolah terdefinisi dengan jelas. Sedangkan Prestasi SD Al Hikmah dapat dilihat dari: 1) Prestasi akademik yag ditunjukkan melalui nilai siswa rata-rata di atas KKM; 2) Penghargaan beberapa perlombaan tingkat nasional dan internasional diantaranya juara lomba budaya mutu sekolah Nasional di Padang tahun 2015; dan 3) 3) Prestasi non akademik, ekstrakulikuler, prestasi bidang ibadah dan akhlak yang sesuai dengan visi sekolah, "Berbudi dan Berprestasi". Sednagkan dalam upaya pengembangkan budaya mutu sekolah, SD Al Hikmah mengacu pada beberapa hal diantaranya orientasi mutu pendidikan, Pelayanan sekolah, komitmen warga sekolah terhadap mutu, dan penerapan kurikulum Diknas, kurkulum lokal khas Al Hikmah, dan Cambridge International Primary Program (CIPP). 


\section{Daftar Rujukan}

Moleong, Lexy J. Metodologi Penelitian Kualitatif, Bandung: PT Remaja Rosdakarya, 1999.

Mulyasa, MenjadiKepala Sekolah Profesional dan menyukseskan MBS dan KBK, Bandung: Remaja Rosdakarya, 2005.

Mustaqim, Sekolah/Madrasah berkualitas dan berkarakter, Jurnal Pendidikan Agama Islam, Semarang : Fakultas Tarbiyah IAIN Walisong, 2012.

Riyanta, Teguh. Mengembangkan Budaya Mutu Sekolah melalui Kepemimpinan Transformasional, Jurnal Manajemen Pendidikan, Vol. 12, No. 2, 2016.

Sallis, Edward. Total Quality Management in Education: Managemen Mutu Pendidikan, Jogjakarta: IRCiSoD, 2006.

Siswanto, Budaya Madrasah: Strategi Pengembangan Mutu Pendidikan, Jurnal Tadris, Vol. 7, No. 2, 2012. 